\title{
Assessment of outcome in hypospadias surgery - a review
}

\author{
Alexander Springer * \\ Department of Pediatric Surgery, Medical University of Vienna, Vienna, Austria
}

Edited by:

Raimund Stein, University of Mainz,

Germany

Reviewed by:

Maya Horst, University Children's

Hospital Zurich, Switzerland

Yuval Bar-Yosef, Tel-Aviv Medical

Center, Israel

Ubirajara Barroso Jr., Federal

University of Bahia, Brazil

Anne-Karoline Ebert, University of

UIm, Germany

*Correspondence:

Alexander Springer, Department of

Pediatric Surgery, Medical University

of Vienna, Währinger Gürtel 18-20,

1090 Vienna, Austria

e-mail: alexander.springer@

meduniwien.ac.at
Hypospadias is a challenging field of urogenital reconstructive surgery with different techniques being currently used. Modern surgery claims that it is possible to create a functionally and cosmetically normal penis. Continuous re-evaluation and assessment of outcome may have a major impact on future clinical practice. Assessment of outcome includes: complication rate, cosmetic appearance of the penis, functional outcome (micturition, sexuality), and psychological factors such as quality of life and psychosexual life. This article briefly reviews current strategies of outcome assessment. Somehow in the future, we will be able to give an accurate estimation of the long-term consequences of being born with hypospadias.

Keywords: hypospadias, complications, assessment, outcome, audit

\section{INTRODUCTION}

Traditionally, successful repair of hypospadias was defined as straight penis in erection and a meatus near the tip of the glans, permitting voiding in a standing position and allowing sexual intercourse. Nevertheless, modern surgery claims that it is possible to create a functionally and cosmetically normal penis. Myriads of techniques have been described and there is still evolution going on. The majority of publications present single-center and single-surgeon retrospective case series with a limited follow-up period and a limited number of patients undergoing follow-up. High-quality randomized trials in pediatric urology are extremely challenging and therefore rarely performed (1). Case series reporting reliable and valid data should include inclusion and exclusion criteria, a detailed description of the surgical procedure, study design, primary and secondary outcome parameters, and followup period and percentage of patients undergoing follow-up (2). There are some systematic reviews and meta-analysis comparing different techniques (3-5). These reviews criticize that there are no standardized algorithms for assessment of outcome. Comparison of studies therefore is complicated, if not impossible. From the clinical point of view, continuous assessment of outcome represents quality control and is part of clinical governance. Continuous re-evaluation may have a major impact on future clinical practice.

Assessment of outcome includes:

- Complications

- Cosmetic appearance of penis

- Functional outcome (micturition, sexuality)

- Quality of life and psychosexual life.

\section{COMPLICATIONS}

The most common complications following hypospadias repair are: urethrocutaneous fistula, meatal stenosis, urethral stricture, urethral diverticulum, glans dehiscence, breakdown, and cosmetic unfavorable outcome requiring redo-surgery. Complication rates depend on many factors which are not subject of this article. Reporting complications also depend on different factors. A recent survey of North American pediatric urologists clearly showed that there is a discrepancy between complication rates reported in the literature and the participants' operative outcomes, regardless of practice setting, operative volume, or time in practice. The reasons for this interesting finding remain unclear (6). However, in an era of economic restraints and academic pressure, publication bias may be a significant factor in reporting complication rates. In a recent international hypospadias survey with nearly 500 participating pediatric urologists and pediatric surgeons, we sought to determine the strategies of follow-up and assessment of outcome (7). It was highly interesting that nearly $60 \%$ of all participants have a follow-up period of less than 6 months. On the other hand, only $10 \%$ of the surgeons would followup their patients until and beyond puberty (unpublished data). However, another survey performed at the 2011 ISHID meeting showed that more than $50 \%$ of the participants would follow their patients until puberty or beyond into adulthood. Table 1 shows randomly selected recent retrospective case series from 2013 (as sorted in PubMed by Recently Added). The range of followup lies between 6 weeks and 9 years. The majority of papers do not address the issue of "lost to follow-up" or "excluded from the study." It has to be assumed that the follow-up rate usually is $100 \%$. It has been criticized that follow-up periods - especially in Northern America - are short, perhaps too short to draw proper conclusions on outcome and complications (8). On the other hand, some believe that most of the complications appear within a short period post-operatively. Therefore, follow-up for 6 months or so appears to be sufficient (9). However, data from Gent show that there is a good long-term outcome without further 


\begin{tabular}{|c|c|c|c|c|}
\hline Reference & Complication rate (\%) & $\begin{array}{l}\text { Follow-up period } \\
\text { (months) }\end{array}$ & Lost to follow-up & Topic \\
\hline Xu et al. (14) & $18.1 / 21.5$ & $22(12-48)$ & Not given, obviously $100 \%$ & TIP vs. island flap \\
\hline Vepakomma et al. (15) & 45.8 & $6-35$ & Not given, obviously $100 \%$ & Modified Koyangi \\
\hline Aslam et al. (17) & 7 & $56(3-103)$ & $5 \%$ & TIP \\
\hline $\begin{array}{l}\text { Kallampallil and } \\
\text { Hennayake (18) }\end{array}$ & $\begin{array}{l}4.3 \text { (urethra), } 18 \\
\text { non-retractile foreskin }\end{array}$ & $27(13-52)$ & $5 \%$ & Foreskin reconstruction \\
\hline Mane et al. (19) & 12 & $32(12-60)$ & Not given, obviously $100 \%$ & Modified TIP \\
\hline Safwat et al. (20) & 28.5 & $52(3-102)$ & Not given, obviously $100 \%$ & Redo-surgery \\
\hline Dutta (24) & 0 & $16(8-38)$ & Not given, obviously $100 \%$ & $\begin{array}{l}\text { Meatal and corpus } \\
\text { spongiosum advancement }\end{array}$ \\
\hline
\end{tabular}

complications in $75 \%$ of the patients. Among the $25 \%$ of patients who needed reoperation, only $47.37 \%$ appeared in the first year after surgery indicating the need for long-term follow-up (10). Moreover, growing and disturbing literature from adult urologists show the limitations of pediatric urologists' view. There is an apprehension that pediatric urologists simply do not have enough epidemiological data on the incidence of failed hypospadias repair in childhood and currently there is no reliable estimation of the number of patients undergoing further surgery in adulthood or redo-surgery (11-13).

\section{ASSESSMENT OF COSMESIS}

Usually, cosmetic appearance is assessed by the surgeon. This is thought to be prone to bias, inaccuracy, and subjectiveness. Asking the parents or the patient (Are you satisfied about the cosmetic outcome? How is the urinary stream? Is the penis straight?) seems also not to be the most objective way to assess critical data. Hadidi proposed a score/assessment sheet including cosmetic and functional outcome and complications (25). It includes size of glans, size/appearance/location of meatus, curvature, complications (fistula, diverticulum, stricture), foreskin appearance, and functional outcome (urinary stream, erection). It is easy to apply, can be kept in the patient's notes, and allows simple retrospective statistical evaluation. However, evaluation is still surgeon dependent. Mureau et al. were one of the first to apply a standardized approach to evaluate patient and surgeon satisfaction with the cosmetic surgical result, and the relation between penile length, meatal position, and patient satisfaction using a genital perception questionnaire for hypospadias patients. Not surprisingly, there was hardly any agreement between patient and surgeon satisfaction with patient penile appearance (26). Holland et al. then introduced the hypospadias objective scoring evaluation (HOSE) system where pediatric surgeons, a nurse, and one of the child's parents independently assessed each patient. They showed that there was little inter-observer variation. The concept still seems very promising (27). There have been refinements like using digital photography with macro mode in a standardized fashion and with more external expertise in judging outcome. The assessment of cosmesis in hypospadias surgery was thought to be more objective when several health professionals, not involved in the surgery, compared the various methods of repair $(28,29)$. The most recent attempt for objective assessment of postoperative outcome is the Pediatric Penile Perception Score (PPPS), which seems to be the most reliable instrument to assess penile self-perception in children after hypospadias repair and for appraisal of the surgical result by parents and uninvolved urologists. The score includes size of penis, glans appearance, appearance of the meatus, penile skin, curvature, etc. rated by patient, parents, and surgeon (30). The PPPS has been validated for pediatric population as well as for adults (then called Penile Perception Score, PPS) (31). The Hypospadias Objective Penile Evaluation Score (HOPE) introduced by a national study group from the Netherlands established objectivity by using standardized photographs, anonymously coded patients, and independent assessment by a panel. They used reference pictures for meatal position and appearance, foreskin, general cosmesis, etc. Statistically, they reached a high intra- and inter-observer reliability, validity, and last but not least a high degree of reproducibility (32). However, there is still debate on what is most reliable and valid way to assess outcome $(33,34)$. Moreover, in most scores the preoperative findings and severity of hypospadias are not taken into account in assessing the final result. A recently developed preoperative Glans-Meatus-Shaft Score (GMS) seems to provide a brief and exact method with a good inter-observer reliability for describing the severity of hypospadias. Additionally, the GMS score appears to correlate with surgical outcome. The score assesses size of the glans, quality of the urethral plate, meatal position, and degree of chordee (35). 
From the practical point of view, it is highly recommended to use standardized assessment tools for comparability and reproducibility, and to build up a prospective database. This can be facilitated as an institutional database, or even more favorable, in a multicenter international standardized database like I-DSD as shown later. Table 2 shows recent assessment tools and their pros and cons.

\section{FUNCTIONAL OUTCOME}

Assessment of functional outcome in non-toilet trained boys is difficult. Functional outcomes are just beginning to be reported in the literature. Besides asking the patient about micturition, urinary flow rates after surgery in older patients have been first reported in 1970s (36). Weak flow rates have been contributed to real stenosis, low vesical pressure, rigidity and low compliance of the neourethra, pseudo-obstruction, and a lack of a natural corpus spongiosum (36). However, these explanations lack supporting evidence. Uroflow data include flow curve shape, maximum flow, micturition volume and post-void residual, and comparison to age-related flow rate nomograms, preferably as defined by the International Children's Continence Society (ICCS) (37). Moreover, it has been well noted that boys with hypospadias show abnormal (though subclinical) flow patterns before and after surgery (38). Many studies support the importance of postoperative uroflow studies (39-42). Some studies show an improving tendency over time. Moreover, some note a weak correlation between flow and clinical symptoms. A recent systematic review recommends a uroflow study after toilet training. Children with obstructed flow parameters or borderline flows should be followed until adulthood. However, until long-term follow-up studies clarify the significance of abnormal flow parameters the significance of these studies remain uncertain (43). Interestingly, neither primary location of the meatus or surgical technique predicts poorer urinary function. However, there seems to be a correlation between severity of chordee and voiding function (41). On the other hand, a recent study describes functional obstruction of the neourethra following TIP defined as persistent obstructive voiding signs and symptoms in spite of apparently successful calibration or dilatation (16). Clinically obvious symptoms like a poor urinary stream, dribbling, incontinence, spraying, or hesitancy may be picked up easily. On the other hand, any subclinical lower urinary tract symptoms, primary or secondary bladder dysfunction, or overactive bladder are difficult to diagnose. These symptoms have been studied by invasive urodynamic studies and overactive is an accompanying entity in hypospadias (44). However, there is no place for routine urodynamic studies in the assessment of hypospadias.

Table 2 | Recent hypospadias assessment tools and their pros and cons.

\begin{tabular}{|c|c|c|c|}
\hline Score & Items & Advantages & Disadvantages \\
\hline HOSE (27) & $\begin{array}{l}\text { Meatal location } \\
\text { Meatal shape } \\
\text { Urinary stream } \\
\text { Erection/curvature } \\
\text { Fistula }\end{array}$ & Inter-observer reliability tested & $\begin{array}{l}\text { Limited items } \\
\text { No general appearance } \\
\text { No penis size } \\
\text { No adequate preoperative assessment }\end{array}$ \\
\hline Mureau (26) & $\begin{array}{l}\text { Flaccid penile size } \\
\text { Penile thickness } \\
\text { Glandular size } \\
\text { Glandular shape } \\
\text { Position of meatus } \\
\text { Scars } \\
\text { Scrotum/testis } \\
\text { General appearance }\end{array}$ & $\begin{array}{l}\text { Assessment of penile size } \\
\text { Not validated }\end{array}$ & $\begin{array}{l}\text { Not tested for reliability and validity } \\
\text { No erection/curvature } \\
\text { Surgically non-correctable items } \\
\text { No adequate preoperative assessment }\end{array}$ \\
\hline PPPS & $\begin{array}{l}\text { Length of penis } \\
\text { Position and shape of meatus } \\
\text { Glandular shape } \\
\text { Erection/curvature } \\
\text { General appearance }\end{array}$ & $\begin{array}{l}\text { High inter-rater reliability } \\
\text { Validated for surgeon and patient }\end{array}$ & $\begin{array}{l}\text { Inherent subjective assessment } \\
\text { No adequate preoperative assessment }\end{array}$ \\
\hline HOPE & $\begin{array}{l}\text { Position of meatus } \\
\text { Meatal shape } \\
\text { Shape of glans } \\
\text { Shape of skin } \\
\text { Penile torsion } \\
\text { Erection/curvature }\end{array}$ & $\begin{array}{l}\text { Reference picture } \\
\text { Implemented into prospective national database }\end{array}$ & $\begin{array}{l}\text { Time consuming } \\
\text { No adequate preoperative assessment }\end{array}$ \\
\hline Hadidi score & Cosmesis and function & Easy to apply & Not validated and prone to subjectiven \\
\hline
\end{tabular}


Table 3 | Follow-up parameters after hypospadias surgery.

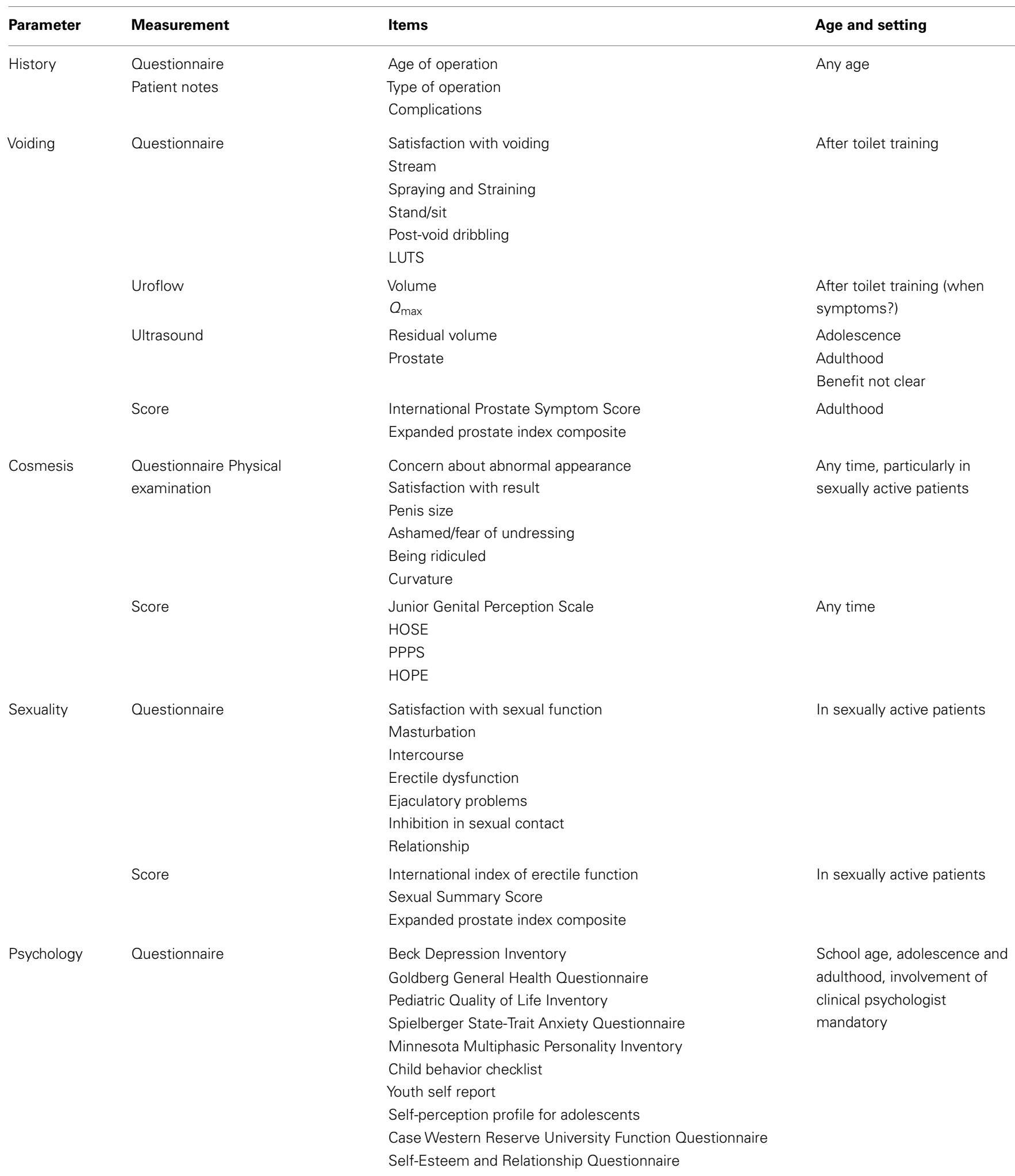

Last but not least, it has to be noted that uroflow studies in small children is very time consuming and can be somewhat frustrating. Although there are no large prospective studies, ultrasound with measurement of post micturition volume may offer another interesting non-invasive technique for postoperative assessment. 


\section{SEXUAL FUNCTION, QUALITY OF LIFE, AND PSYCHOSEXUAL}

LIFE

Sexual behavior and sexual function after surgery in young adults are delicate topics and very demanding to assess. There are some studies assessing long-term psychosexual adjustment and sexual function matched with control groups including strength of libido, strength and duration of erection, penile appearance, penile size, curvature, problems with ejaculation (spraying, dribbling, retrograde ejaculation, premature ejaculation), masturbation activity, sexual activity, problems with intercourse, number of sexual partners, intimate relationships, and satisfaction with sexual life in general. These data show that patients with previous hypospadias surgery in general have rather good sexual function. However, there are differences in certain aspects of sexual behavior between patients with hypospadias and controls. Patients who had been operated for hypospadias are concerned about penile appearance. Particularly, penile size can obviously impact satisfaction (as in normal population). The more severe the hypospadias, the more dissatisfactory the long-term outcome and better cosmetic outcome is related to better sexual outcome. Recent data show a relatively high incidence of erectile dysfunction and premature ejaculation (45-48). A Swiss study showed a lower self-reported health-related quality (HRQ) of life in boys and adolescents following hypospadias repair related to penile self-perception fear of being ridiculed etc (49). Another recent Swiss study comparing adults who had hypospadias repair in childhood with a control group of circumcised men suggested that the HRQ is quite similar. However, poor genital self-perception again is correlated with an impaired mental HRQ (50). A case-control study from China showed that the incidence of anxiety and depression was significantly higher in adults following hypospadias repair. There was a correlation between the severity of symptoms and age at operation and penile size (51). Another Chinese study clearly showed that penile appearance and size of the penis have a major impact on psychosexual health (45). A small but promising study with adolescents following hypospadias repair showed that although there is impairment of body image and genital perception, the overall social, psychosocial, and sexual development seems to be normal (52). A systematic review from 2008 including only 13 studies with inconsistent quality showed that boys with hypospadias suffer from negative genital appraisal and sexual inhibitions. Psychological factors remain unclear (53). Surgery in the future will have to take much more into consideration the long-term consequences of esthetic and functional penile reconstruction in early childhood and how it will affect the patient in his later life physically, mentally, and emotionally.

A recent systematic review by Rynja et al. showed that there is a substantial lack in cosmetic, functional, and psychological long-term data. Moreover, quality of data is corrupted by low follow-up rate, heterogeneous patients and data, and a lack of validated questionnaires and control groups (54). Table 3 shows a number of parameters of follow-up which could be evaluated and surveyed in prospective long-term studies. Most surgeons would agree that the patient routinely should be seen within the first year of operation to assess short term outcome and to pick up complications. Voiding preferably is assed after toilet training. Yearly follow-up is desirable but extremely difficult to maintain.
However, it is strongly recommended that the patient is seen after puberty (penile growth), as adolescent and sexually active man. It is a long way to go. However, there are promising studies coming up, e.g., the web-based prospective multicenter study by the Dutch Hypospadias Study Group. Another prospective multicenter online database will be installed in the I-DSD registry (www.i-dsd.org). The I-DSD registry is run by the I-DSD network which is a 5-year Medical Research Council funded initiative to support the development of an International DSD registry and network of clinical and research partners. The registry provides a means of connecting clinical and research centers around the world within a virtual environment and allows these experts to enter standardized information that will improve clinical practice, research, and understanding of these challenging conditions (55). Currently, a module for preoperative and postoperative assessment of hypospadias with the possibility of a prospective long-term follow-up regime is under development. International hypospadias surgeons will be invited to join the I-DSD registry and register their patients prospectively.

\section{CONCLUSION}

Follow-up and adequate counseling of hypospadias patients up to adult life is necessary, although demanding. Long-term assessment should be designed in prospective studies. Somehow in the future, we will be able to give an accurate estimation of the long-term consequences of being born with hypospadias.

\section{REFERENCES}

1. Springer A, Subramaniam R, Tekgul S, Riedmiller H, Hoebeke P, Kocvara R, et al. EAU guidelines on vesicoureteral reflux in children. Eur Urol (2012) 62:534-42. doi:10.1016/j.eururo.2012.05.059

2. Snodgrass W. Hypospadias reporting - how good is the literature? J Urol (2010) 184:1255-6. doi:10.1016/j.juro.2010.07.006

3. Castagnetti M, El-Ghoneimi A. Surgical management of primary severe hypospadias in children: systematic 20-year review. J Urol (2010) 184:1469-74. doi:10.1016/j.juro.2010.06.044

4. Braga LH, Lorenzo AJ, Salle JL. Tubularized incised plate urethroplasty for distal hypospadias: a literature review. Indian J Urol (2008) 24:219-25. doi:10.4103/ 0970-1591.40619

5. Wang F, Xu Y, Zhong H. Systematic review and meta-analysis of studies comparing the perimeatal-based flap and tubularized incised-plate techniques for primary hypospadias repair. Pediatr Surg Int (2013) 29:811-21. doi:10.1007/ s00383-013-3335-3

6. Prasad MM, Marks A, Vasquez E, Yerkes EB, Cheng EY. Published surgical success rates in pediatric urology - fact or fiction? J Urol (2012) 188:1643-7. doi:10.1016/j.juro.2012.02.032

7. Springer A, Krois W, Horcher E. Trends in hypospadias surgery: results of a worldwide survey. Eur Urol (2011) 60:1184-9. doi:10.1016/j.eururo.2011.08.031

8. González R, Ludwikowski B, Silay MS, Sirin H, Tepeler A, Karatag T, et al. "Snodgraft" technique for the treatment of primary distal hypospadias: pushing the envelope. J Urol (2012) 188:938-42. doi:10.1016/j.juro.2012.04.126

9. Snodgrass W, Macedo A, Hoebeke P, Mouriquand PDE, et al. Hypospadias dilemmas: a round table. J Pediatr Urol (2011) 7:145-57. doi:10.1016/j.jpurol. 2010.11.009

10. Spinoit AF, Poelaert F, Groen LA, Van Laecke E, Hoebeke P. Hypospadias repair at a tertiary care center: long-term followup is mandatory to determine the rea complication rate. J Urol (2013) 189:2276-81. doi:10.1016/j.juro.2012.12.100

11. Barbagli G, Perovic S, Djinovic R, Sansalone S, Lazzeri M. Retrospective descriptive analysis of 1,176 patients with failed hypospadias repair. J Urol (2010) 183:207-11. doi:10.1016/j.juro.2009.08.153

12. Perovic S, Barbagli G, Djinovic R, Sansalone S, Vallasciani S, Lazzeri M. Surgical challenge in patients who underwent failed hypospadias repair: is it time to change? Urol Int (2010) 85:427-35. doi:10.1159/000319856 
13. Mundy AR. Failed hypospadias repair presenting in adults. Eur Urol (2006) 49:774-6. doi:10.1016/j.eururo.2006.02.015

14. Xu N, Xue XY, Li XD, Wei Y, Zheng QS, Jiang T, et al. Comparative outcomes of the tubularized incised plate and transverse island flap onlay techniques for the repair of proximal hypospadias. Int Urol Nephrol (2013). doi:10.1007/s11255-013-0567-z

15. Vepakomma D, Alladi A, Ramareddy RS, Akhtar T. Modified koyanagi repair for severe hypospadias. J Indian Assoc Pediatr Surg (2013) 18:96-9. doi:10.4103/ 0971-9261.116041

16. Hadidi AT. Functional urethral obstruction following tubularised incised plate repair of hypospadias. J Pediatr Surg (2013) 48:1778-83. doi:10.1016/j.jpedsurg. 2012.10.071

17. Aslam R, Campbell K, Wharton S, Bracka A. Medium to long term results following single stage Snodgrass hypospadias repair. J Plast Reconstr Aesthet Surg (2013) 66:1591-5. doi:10.1016/j.bjps.2013.06.041

18. Kallampallil J, Hennayake S. Foreskin retractility following hypospadias repair with preputioplasty - medium term outcomes. J Pediatr Urol (2013) 9(Pt B):1204-9. doi:10.1016/j.jpurol.2013.05.022

19. Mane S, Arlikar J, Dhende N. Modified tubularized incised plate urethroplasty. J Indian Assoc Pediatr Surg (2013) 18:62-5. doi:10.4103/0971-9261.109354

20. Safwat AS, Elderwy A, Hammouda HM. Which type of urethroplasty in failed hypospadias repair? An 8-year follow up. J Pediatr Urol (2013) 9(Pt B):1150-4. doi:10.1016/j.jpurol.2013.04.015

21. Snodgrass WT, Granberg C, Bush NC. Urethral strictures following urethral plate and proximal urethral elevation during proximal TIP hypospadias repair. J Pediatr Urol (2013) 9(Pt B):990-4. doi:10.1016/j.jpurol.2013.04.005

22. Chandrasekharam VV. Single-stage repair of hypospadias using longitudinal dorsal island flap: single-surgeon experience with 102 cases. Indian J Urol (2013) 29:48-52. doi:10.4103/0970-1591.109984

23. El dahshoury ZM, Gamal W, Hammady A, Hussein M, Salem E. Modified double face onlay island preputial skin flap with augmented glanuloplasty for hypospadias repair. J Pediatr Urol (2013) 9(Pt A):745-9. doi:10.1016/j.jpurol. 2013.03.005

24. Dutta HK. Meatal and corpus spongiosum advancement: a better technique for distal hypospadias repair. Pediatr Surg Int (2013) 29:633-8. doi:10.1007/s00383013-3292-x

25. Hadidi AT. Assessement of outcome. In: Hadidi AT, Azmy AF, editors. Hypospadias Surgery. Heidelberg: Springer (2004). p. 90-2.

26. Mureau MA, Slijper FM, Slob AK, Verhulst FC, Nijman RJ. Satisfaction with penile appearance after hypospadias surgery: the patient and surgeon view. JUrol (1996) 155:703-6. doi:10.1016/S0022-5347(01)66504-2

27. Holland AJ, Smith GH, Ross FI, Cass DT. HOSE: an objective scoring system for evaluating the results of hypospadias surgery. BJU Int (2001) 88:255-8. doi:10.1046/j.1464-410x.2001.02280.x

28. Ververidis M, Dickson AP, Gough DCS. An objective assessment of the results of hypospadias surgery. BJU Int (2005) 96:135-9. doi:10.1111/j.1464-410X.2005. 05582.x

29. Baskin L. Hypospadias: a critical analysis of cosmetic outcomes using photography. BJU Int (2001) 87:534-9. doi:10.1046/j.1464-410X.2001.00092.x

30. Weber DM, Schonbucher VB, Landolt MA, Gobet R. The Pediatric Penile Perception Score: an instrument for patient self-assessment and surgeon evaluation after hypospadias repair. J Urol (2008) 180:1080-4. doi:10.1016/j.juro.2008.05. 060 discussion 1084

31. Weber DM, Landolt MA, Gobet R, Kalisch M, Greeff NK. The Penile Perception Score: an instrument enabling evaluation by surgeons and patient selfassessment after hypospadias repair. J Urol (2013) 189:189-93. doi:10.1016/j. juro.2012.08.178

32. van der Toorn F, de Jong TP, de Gier RP, Callewaert PR, van der Horst EH, Steffens MG, et al. Introducing the HOPE (Hypospadias Objective Penile Evaluation)score: a validation study of an objective scoring system for evaluating cosmetic appearance in hypospadias patients. J Pediatr Urol (2013) 9(Pt B):1006-16. doi:10.1016/j.jpurol.2013.01.015

33. van der Toorn F. Response to Letter to the Editor RE: introducing the HOPE (Hypospadias Objective Penile Evaluation)-score: a validation study of an objective scoring system for evaluating cosmetic appearance in hypospadias patients. J Pediatr Urol (2013) 9:1017. doi:10.1016/j.jpurol.2013.01.015

34. Weber DM. RE: introducing the HOPE (Hypospadias Objective Penile Evaluation)-score: a validation study of an objective scoring system for evaluating cosmetic appearance in hypospadias patients. J Pediatr Urol (2013) 9:1016. doi:10.1016/j.jpurol.2013.07.022

35. Merriman LS, Arlen AM, Broecker BH, Smith EA, Kirsch AJ, Elmore JM. The GMS hypospadias score: assessment of inter-observer reliability and correlation with post-operative complications. J Pediatr Urol (2013) 9(Pt A):707-12. doi:10.1016/j.jpurol.2013.04.006

36. Page RE, Akin Y. Assessment of urine flow in hypospadias. Br J Plast Surg (1978) 31:313-6. doi:10.1016/0007-1226(78)90117-0

37. Nevéus T, von Gontard A, Hoebeke P, Hjälmås K, Bauer S, Bower W, et al. The standardization of terminology of lower urinary tract function in children and adolescents: report from the Standardisation Committee of the International Children's Continence Society. J Urol (2006) 176:314-24. doi:10.1016/S00225347(06)00305-3

38. Wolffenbuttel KP, Wondergem N, Hoefnagels JJ, Dieleman GC, Pel JJ, Passchier BT, et al. Abnormal urine flow in boys with distal hypospadias before and after correction. J Urol (2006) 176:1733-6. doi:10.1016/S0022-5347(06)00614-8 discussion 1736-7

39. Garibay JT, Reid C, Gonzalez R. Functional evaluation of the results of hypospadias surgery with uroflowmetry. J Urol (1995) 154:835-6. doi:10.1097/ 00005392-199508000-00137

40. Olsen LH, Grothe I, Rawashdeh YF, Jørgensen TM. Urinary flow patterns in infants with distal hypospadias. J Pediatr Urol (2011) 7:428-32. doi:10.1016/j. jpurol.2010.05.013

41. Perera M, Jones B, O’Brien M, Hutson JM. Long-term urethral function measured by uroflowmetry after hypospadias surgery: comparison with an age matched control. J Urol (2012) 188:1457-62. doi:10.1016/j.juro.2012.04.105

42. van derWerff JF, Boeve E, Brussé CA, van derMeulen JC. Urodynamic evaluation of hypospadias repair. J Urol (1997) 157:1344-6. doi:10.1097/00005392199704000-00047

43. González R, Ludwikowski BM. Importance of urinary flow studies after hypospadias repair: a systematic review. Int J Urol (2011) 18:757-61. doi:10. 1111/j.1442-2042.2011.02839.x

44. Ozkurkcugil C, Guvenc BH, Dillioglugil O. First report of overactive detrusor in association with hypospadias detected by urodynamic screening. Neurourol Urodyn (2005) 24:77-80. doi:10.1002/nau.20072

45. Jiao C, Wu R, Xu X, Yu Q. Long-term outcome of penile appearance and sexual function after hypospadias repairs: situation and relation. Int Urol Nephrol (2011) 43:47-54. doi:10.1007/s11255-010-9775-y

46. Bubanj TB, Perovic SV, Milicevic RM, Jovcic SB, Marjanovic ZO, Djordjevic MM. Sexual behavior and sexual function of adults after hypospadias surgery: a comparative study. J Urol (2004) 171:1876-9. doi:10.1097/01.ju.0000119337. 19471.51

47. Rynja SP, Wouters GA, Van Schaijk M, Kok ET, De Jong TP, De Kort LM. Longterm followup of hypospadias: functional and cosmetic results. J Urol (2009) 182:1736-43. doi:10.1016/j.juro.2009.03.073

48. Chertin B, Natsheh A, Ben-Zion I, Prat D, Kocherov S, Farkas A, et al. Objective and subjective sexual outcomes in adult patients after hypospadias repair performed in childhood. J Urol (2013) 190:1556-60. doi:10.1016/j.juro. 2012.12.104

49. Schönbucher VB, Landolt MA, Gobet R, Weber DM. Health-related quality of life and psychological adjustment of children and adolescents with hypospadias. J Pediatr (2008) 152:865-72. doi:10.1016/j.jpeds.2007.11.036

50. Ruppen-Greeff NK, Weber DM, Gobet R, Landolt MA. Health-related quality of life in men with corrected hypospadias: an explorative study. J Pediatr Urol (2013) 9:551-8. doi:10.1016/j.jpurol.2013.04.016

51. Wang WW, Deng CH, Chen LW, Zhao LY, Mo JC, Tu XA. Psychosexual adjustment and age factors in 130 men undergone hypospadias surgery in a Chinese hospital. Andrologia (2010) 42:384-8. doi:10.1111/j.1439-0272.2010.01061.x

52. Vandendriessche S, Baeyens D, Van Hoecke E, Indekeu A, Hoebeke P. Body image and sexuality in adolescents after hypospadias surgery. J Pediatr Urol (2010) 6:54-9. doi:10.1016/j.jpurol.2009.04.009

53. Schonbucher VB, Weber DM, Landolt MA. Psychosocial adjustment, healthrelated quality of life, and psychosexual development of boys with hypospadias: a systematic review. J Pediatr Psychol (2008) 33:520-35. doi:10.1093/jpepsy/ jsm098

54. Rynja SP, de Jong TP, Bosch JL, de Kort LM. Functional, cosmetic and psychosexual results in adult men who underwent hypospadias correction in childhood. J Pediatr Urol (2011) 7:504-15. doi:10.1016/j.jpurol.2011.02.008 
55. I-DSD Network. Available from: http://www.gla.ac.uk/schools/medicine/ medicine/childhealth/i-dsdproject/ (2013).

Conflict of Interest Statement: The author declares that the research was conducted in the absence of any commercial or financial relationships that could be construed as a potential conflict of interest.

Received: 06 October 2013; accepted: 04 January 2014; published online: 20 January 2014.
Citation: Springer A (2014) Assessment of outcome in hypospadias surgery - a review. Front. Pediatr. 2:2. doi: 10.3389/fped.2014.00002

This article was submitted to Pediatric Urology, a section of the journal Frontiers in Pediatrics.

Copyright $\odot 2014$ Springer. This is an open-access article distributed under the terms of the Creative Commons Attribution License (CC BY). The use, distribution or reproduction in other forums is permitted, provided the original author(s) or licensor are credited and that the original publication in this journal is cited, in accordance with accepted academic practice. No use, distribution or reproduction is permitted which does not comply with these terms. 